\title{
Coevolution Between Food-Rewarding Flowers and Their Pollinators
}

\author{
Steven D. Johnson • Bruce Anderson
}

Published online: 13 January 2010

(C) Springer Science+Business Media, LLC 2010

\begin{abstract}
The concept of coevolution was first developed by Darwin, who used it to explain how pollinators and food-rewarding flowers involved in specialized mutualisms could, over time, develop long tongues and deep tubes, respectively. He famously predicted that Angraecum sesquipedale, a long-spurred Malagasy orchid, must be pollinated by a hawkmoth with an exceptionally long tongue. Darwin's idea of a coevolutionary "race" was championed by contemporary naturalists, including Alfred Wallace, and a hawkmoth fitting the expected tonguelength profile was eventually discovered in Madagascar during the early twentieth century. However, strong empirical support for the mechanism behind Darwin's coevolutionary model has been forthcoming only in the past two decades. It is now established that selection often strongly favors plants with floral tubes that exceed the length of their pollinator's tongues. There is also evidence that pollinators gain an energetic benefit from having tongues that enable them to consume most or all of the nectar in deep tubular flowers. Alternative explanations for the evolution of long pollinator tongues, such as evasion of predators that use flowers as ambush sites, are considered much less compelling and lack quantitative support. Another important advance in coevolution research has been the development of approaches that explicitly predict
\end{abstract}

S. D. Johnson $(\bowtie)$

School of Biological and Conservation Sciences,

University of KwaZulu-Natal,

P. Bag X01,

Scottsville, Pietermaritzburg 3209, South Africa

e-mail: Johnsonsd@ukzn.ac.za

B. Anderson

Department of Botany and Zoology, University of Stellenbosch,

P. Bag. X1, Matieland, Stellenbosch 7602, South Africa a geographical mosaic of coevolution. The expectation that coevolution can lead to geographical diversification and trait covariation among strongly interacting organisms is strongly supported by studies of long-proboscid fly and oilbee pollination systems in South Africa. Macro- and microevolutionary studies of pollination systems suggest that coevolution can operate alongside other one-sided evolutionary processes, such as shifts, in shaping plant and pollinator traits.

Keywords Coevolutionary arms race $\cdot$ Ecotype $\cdot$ Pollination syndrome $\cdot$ Geographic mosaic $\cdot$ Natural selection $\cdot$ Nectar

\section{Introduction}

It is widely accepted that angiosperm flowers and their insect pollinators have influenced each other's evolution, but there is still considerable uncertainty about whether or not coevolution has been a major process in the diversification of these groups. Coevolution is most likely when interacting organisms have strong effects on each other's fitness (Thompson 1994). This criterion is clearly met for pollination mutualisms in which the insects that pollinate plants also depend on them as brood sites (Thompson 1994). Classic examples of such coevolved brood-site pollination mutualisms are the relationships between figs and agaoinid fig-wasps and between yuccas and Tegiticula moths (Pellmyr et al. 1996; Sakai 2002; Weiblen 2002).

More controversial has been the role of coevolution in shaping the relationships between plants with foodrewarding flowers and their pollinators (Schemske 1983; Nilsson 1998). The main basis for the controversy has been the disagreement over the level of specialization in these plant-pollinator interactions and the role of pollinator shifts 
versus coevolution in shaping traits (Wasserthal 1997; Whittall and Hodges 2007). While many plants have flowers specialized for a single functional group of pollinators, such as moths or bees, and sometimes even a single pollinator species, it is relatively rare for insect pollinators to specialize on flowers of a particular plant species. This asymmetry in specialization is now well documented by studies of networks of interactions between flowers and their animal visitors (Vazquez and Aizen 2004). Although this leads to an expectation of weak or diffuse coevolution at the level of interacting species, it has been pointed out that generalist species often interact with a relatively small subset of species at the local site level, and this could lead to a complex geographical mosaic of coevolutionary interactions (Thompson 1994, 2005).

In this contribution, we outline the historical development of the idea of plant-pollinator coevolution and then discuss recent studies of coevolution between food-rewarding flowers and their pollinators. These examples which deal with longtubed flowers and long-tongued (and, in one unusual case, long-legged) pollinators can be used to teach key concepts in evolutionary biology, including adaptation through natural selection, coevolution, and geographical divergence.

\section{Darwin's Mechanistic Model}

The concept of coevolution is often attributed to Ehrlich and Raven's classic paper on butterflies and their larval host plants (Ehrlich and Raven 1964). However, the original idea can be traced to Darwin $(1859,1862)$. General remarks about co-adaptation between flowers and pollinators first appeared in the Origin, but Darwin developed the concept more explicitly in his subsequent book on orchid pollination (Darwin 1862).

In hypothesizing how the Malagasy star orchid (Angraecum sesquipedale) might have evolved its extraordinarily long (c. 30 centimeters) nectar spur, Darwin (1862) proposed the first mechanistic model of the coevolutionary process. Although he never used the term coevolution, he did refer to "a race in gaining length between the nectary of Angraecum and the proboscis of certain moths" (Darwin 1862). He noticed that the Angraecum, like the local British moth-pollinated Platanthera orchids, had nectar at the very bottom of the long spur and that moths would require a long proboscis in order to claim this reward. The fittest moths in a population would then be those with long tongues that could access the nectar in even the deepest flowers, whereas the shorter-tongued moths would access less nectar (Fig. 1). Thus, moths would be expected to be under strong directional selection and should evolve greater tongue lengths (Fig. 1). By inserting rods of different diameter into flowers, Darwin ascertained that pollen would only be

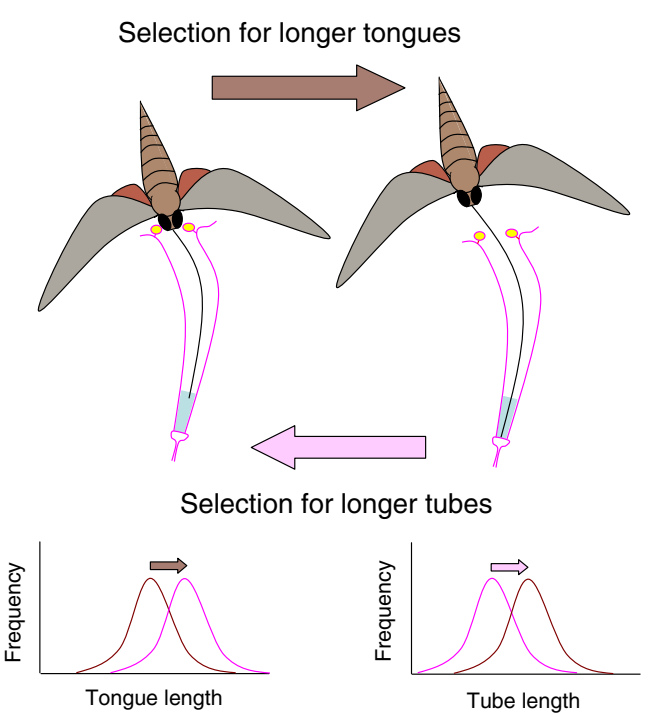

Fig. 1 Darwin's mechanistic model for plant-pollinator coevolution

transferred between moths and Angraecum orchids if the moths push the thickened base of their proboscis right up against the reproductive parts of the flower when they try to drain the last drops of nectar from the bottom of the nectar spur. Thus, the fittest orchids would be those with spurs that are longer than the tongues of all the visiting moths (Fig. 1). Orchids with spurs that are shorter than the tongues of some visiting moths would not be effectively pollinated, as the moths would not make sufficient contact with the reproductive parts of the flower. If, in every generation, the orchids evolved longer spurs, moths too would have to evolve longer tongues, and so on. This is the basis of Darwin's "race," commonly known as "escalatory coevolution," which can lead to the evolution of extreme traits, such as those possessed by some flowers and their pollinators. Most pollinators and plants do not possess such extreme traits because the coevolutionary cycle is halted early in the process by selective pressures which oppose continued lengthening, for example flight constraints associated with maneuvering an elongated proboscis.

Darwin (1862) was confident enough about the pollination mechanism of $A$. sequipedale to predict the existence of its pollinator, a hawkmoth with a tongue "capable of extension to a length of between 10 and 11 inches [25 centimeters]!" Darwin's Angraecum hypothesis was championed enthusiastically by Alfred Wallace (1867) in his essay "Creation by Law" written as a rebuttal of an earlier anti-evolution essay in the same journal by the Duke of Argyll, George Douglas Campbell. In his essay, Wallace elaborated on Darwin's mechanism and included an illustration which showed the hypothetical hawkmoth in the act of pollinating the Angraecum orchid (Fig. 2). In a personal letter to Wallace, Darwin was generally favorable about the essay but critical about the proportions of the moth, which has wings resembling those of 


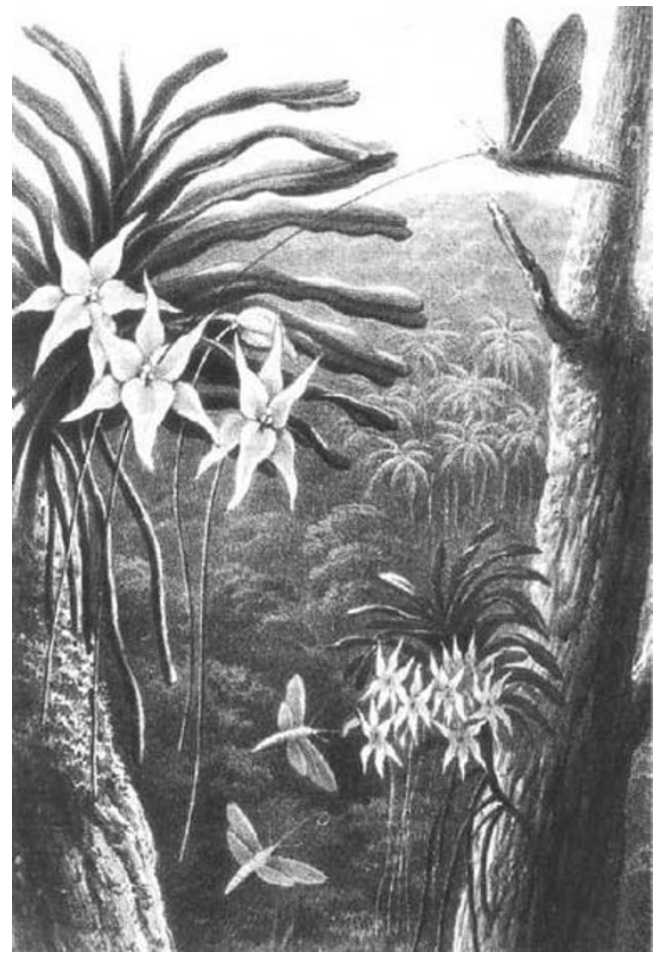

Fig. 2 Illustration of Angraecum being pollinated by a long-tongued hawkmoth, as predicted by Darwin. From the essay Creation by Law by Wallace (1867)

a huge flying termite: "I am glad you had the courage to take up Angraeceum after the Duke's attack; for I believe the principle in this case may be widely applied. I like the Figure but I wish the artist had drawn a better sphinx" (Darwin 1867).

Wallace's essay was remarkable for two reasons: First, it conveys a sophisticated understanding of the nature of selection among individuals belonging to a normal distribution of trait values. "The flowers most completely fertilized by these moths being those which had the longest nectaries, there would in each generation be on the average an increase in the length of the nectaries, and also an average increase in the length of the proboscis of the moths, and this would be a necessary result from the fact that nature ever fluctuates about a mean, or that in every generation there would be flowers with longer and shorter nectaries, and moths with longer and shorter probosces than the average" ( $\mathrm{p} 476$ ). Second, Wallace actually mentions Xanthopan (Macrosila) morganii, the species of moth that is now considered the most likely pollinator of $A$. sesquipedale. Wallace was not aware of the long-tongued Malagasy race of this hawkmoth, but he had measured a specimen of the African mainland form in the British Museum and found that its tongue measured 7.5 inches [18 centimeters]. Wallace (1867) wrote "That such a moth exists in Madagascar may be safely predicted; and naturalists who visit that island should search for it with as much confidence as astronomers searched for the planet Neptune,- - and they will be equally successful!"
A further indication that Darwin's prediction would prove correct came when the naturalist Herman Müller (1873) reported that his brother Fritz had encountered hawkmoths in South America that had tongues as long as 30 centimeters. Although Xanthopan morganii praedicta, the long-tongued Malagasy form of $X$. morganii, was described in 1903, direct observations of this moth pollinating A. sequipedale in the wild are still lacking. A specimen has been found with remains of an A. sesquipedale pollinarium on its tongue and captive individuals have been photographed while visiting the orchid in large flight cages and shown to be effective pollinators under these conditions (Wasserthal 1997). However, interactions between other long-spurred angraecoid orchids and very long-tongued hawkmoths in Madagascar and the African mainland are now well documented in the wild (Nilsson et al. 1985; Martins and Johnson 2007).

\section{Alternative Mechanisms: The Pollinator Shift Model}

Coevolution is not the only process that can account for the evolution of long floral tubes. The most plausible alternative is that tube length evolves when plants undergo evolutionary shifts between different pollinators. The pollinator shift model was developed by Verne Grant (Grant and Grant 1965) and Ledyard Stebbins (Stebbins 1970). In this model, pollinator shifts (utilization of different pollinators through modification of floral traits) are induced by changes in the local pollinator fauna, either because of expansion of a species range or because of a change in pollinator composition over time (Johnson 2006). In the shift model, plants adapt to pollinators with preexisting tongue lengths (one-sided evolution), but the mechanism of selection on corolla tube length is usually identical to that in the Darwin model (Fig. 1) Studies of the African Disa draconis complex of orchids showed that spur length evolution could be explained by shifts between pollinators (Johnson and Steiner 1997). In his study of A. sesquipedale, Wasserthal (1997) concluded that the pollinator shift model, rather than coevolution, could explain the evolution of the very long spurs of this species.

Wasserthal's rejection of the coevolution model was based on his belief that hawkmoth tongues evolve primarily under directional selection from ambush predators such as spiders in flowers (Wasserthal 1997; see below). A more compelling reason to doubt that pairwise coevolution has shaped the Angraecum-hawkmoth system is that the orchid is naturally rare, and if we assume that this was also the case in historical times, then it was unlikely to have had a strong influence on the evolution of the tongue of $X$. morganii or any other hawkmoth (Whittall and Hodges 2007). These uncertainties highlight the fact that coevolutionary problems cannot be solved by studying single species at single sites 
and, instead, require comparative approaches that include studies of whole guilds of interacting species across their geographical ranges (see below).

\section{Selection on Flower Tube Length}

In a landmark test of Darwin's mechanism of selection on flower tube length, the Swedish pollination biologist Anders Nilsson experimentally shortened spurs of the hawkmothpollinated European orchid Platanthera bifolia. His findings were, in accordance with Darwin's idea, that flowers with experimentally shortened spurs experienced lower levels of pollen deposition and removal (Nilsson 1988). Alexandersson and Johnson (2002) later demonstrated a positive relationship between fitness (measured by the number of seeds produced) and naturally varying corolla tube length in the hawkmoth-pollinated Iris Gladiolus longicollis. Plants with shorter tubes were not effectively pollinated because of their mismatch with the tongue lengths of the majority of individuals of the hawkmoth pollinator Agrius convolvuli (range in tongue length: 85-135 millimeters). Similar results have been obtained in studies of selection on tube length in flowers pollinated by long-proboscid flies (Johnson and Steiner 1997; Anderson and Johnson 2008, 2009; Pauw et al. 2009). For example, mismatches in the length of the proboscis of the fly Moegistorhynchus longirostris and the tube length of its nectar host plant Lapeirousia anceps (Fig. 3) lead to lowered pollination success (Pauw et al. 2009).

The general principle that selection favors flower tubes that are longer than the tongues of animal visitors was recently extended to interactions between long-tubed (80 90 millimeters) flowers of the plant Centropogon nigricans and its specialist pollinator, the long-tongued bat Anoura fistulata (Muchhala and Thomson 2009). The tongue, which is stored in a modified thoracic cavity, has similar dimensions to the plant tube lengths and can be extended 1.5 times the body length of the bat. In flight cage experiments in which flowers were offered to Anoura bats, flowers with long tubes received more pollen and also exported more pollen to other flowers than did short-tubed flowers.

\section{Selection on Pollinator Tongue Length}

Long tongues have evolved in many groups of flowervisiting animals, including hummingbirds (bills up to 10 centimeters), hawkmoths (tongues up to 25 centimeters), and nemestrinid flies (tongues up to 8 centimeters), and it seems fairly obvious that the elongation of these tongues represents adaptation for feeding on nectar. In one of the few demonstrations of the utility of long tongues, Pauw et al. (2009) presented flowers singly to foraging nemestrinid flies (M. longirostris) and found that individuals with longer tongue lengths were able to drink more nectar in a single visit to the deep-tubed flowers of the iris $L$. anceps. Although this study did not include a measure of the efficiency of feeding (nectar consumed per unit time), it did confirm that directional selection on tongue length could potentially occur through an energetic benefit.

As an alternative to the nectar access hypothesis, Wasserthal (1997) has argued that the evolution of long
Fig. 3 Nemestrinid flies $M$. longirostris with a tongue length of approximately 50 millimeters probe flowers of two morphs of $L$. anceps that differ in tube length. a Longtubed flowers (53 millimeters) that match the length of a fly which has not yet fully inserted its proboscis. b Short-tubed flowers (28 millimeters) that are mismatched to the proboscis of a fly and thus receive less pollen on stigmas (Pauw et al. 2009). Photos: Steve Johnson

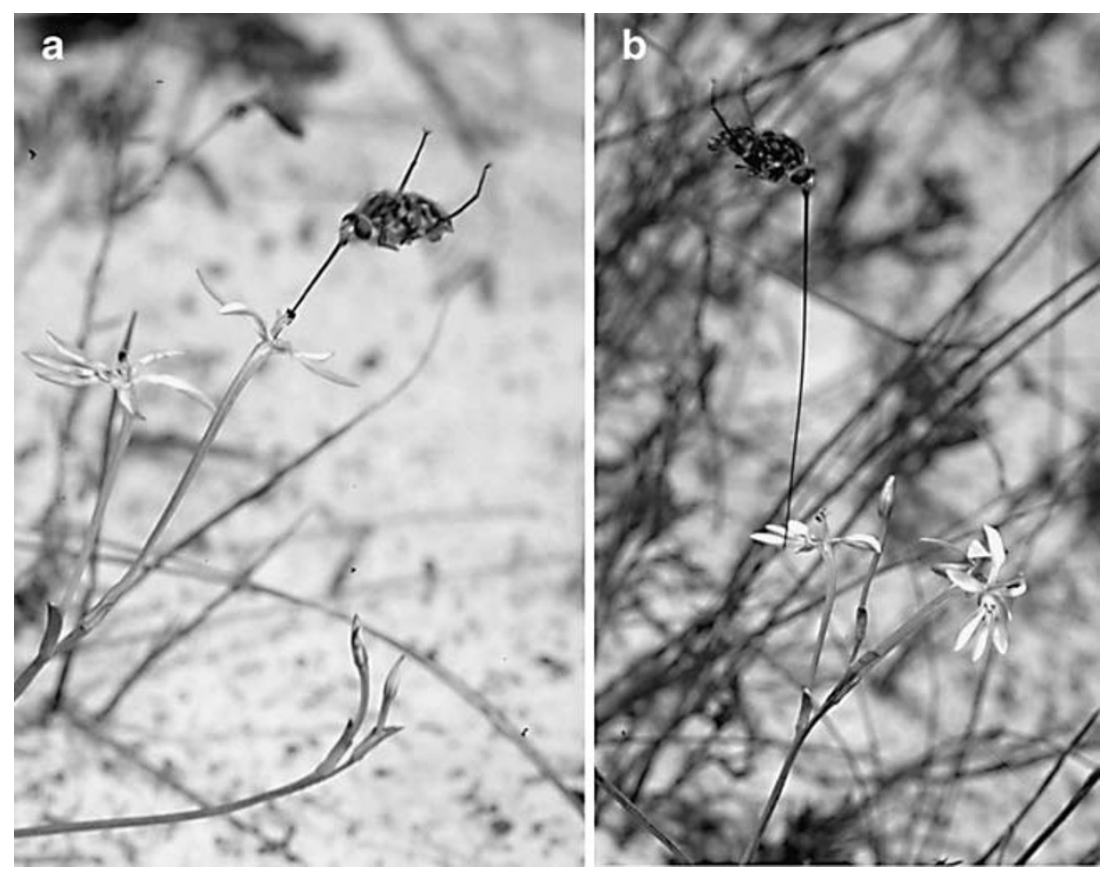


tongues in flower-visiting animals has been driven by directional selection from ambush predators in flowers. The basis of his claim is that long-tongued hawkmoths are generalist foragers that frequently feed on short-tubed flowers and sometimes do so while violently swinging their bodies from side to side, behavior which can be triggered by the presence of spiders in flowers. He interprets the long tongues and the behavior as traits selected by predators. However, as was pointed out by Nilsson (1998), naturalists who have worked on hawkmothpollinated flowers seldom find any spiders large enough to prey on hawkmoths, and so the predation avoidance hypothesis remains unsupported by any hard evidence. Another potential explanation for long tongues in flowerfeeding animals is that they simply reflect an allometric relation with body size; however, several studies have shown that the evolution of tongue lengths (and even leg lengths) in flower-feeding animals is not closely coupled to body size (Steiner and Whitehead 1990; Anderson and Johnson 2008; Pauw et al. 2009).

\section{Geographical Patterns of Coevolution in a Community Context}

Selective pressures on pollinator tongues and tubes are not uniform across geographic landscapes because interacting organisms seldom have precisely overlapping distribution ranges (Grant and Grant 1965). As a result, plants may have different floral visitors in different populations, and floral visitors may forage from different plant communities in different parts of their range. For example, Gomez et al. (2009) found that the mustard Erysimum mediohispanicum has very different pollinator communities in different populations and that this accounted for differences among the populations in selection on traits such as corolla width and shape. Although not an example of coevolution, the results of this study predict that coevolutionary relationships should also have geographically variable outcomes when community structure differs. This is an important idea which has been developed over the last few decades by John Thompson and his colleagues (Thompson 1994, 2005).

Community composition has been shown to influence whether a relationship between an interacting species pair is mutualistic, commensalistic, or antagonistic (e.g., Thompson and Cunningham 2002). Similarly, in other pollination relationships, it can be imagined that the strength and even direction of selection exerted by one partner on the other would also be dependent on community context. For example, a community of long-tubed plants may select strongly for pollinators with long tongues. However, a community of mixed long- and short-tubed species may not select very strongly for long-tongued pollinators but may in fact select for pollinators with shorter tongues. As the pollinators evolve shorter tongues, they may then also select for shorter tubes in the long-tubed plant species. One outcome of this may be a landscape where tube and tongue lengths match each other closely in each population but where the magnitude of morphological traits differs between populations. This was first observed in oil-collecting bees and the flowers that they visit (Steiner and Whitehead 1990, 1991). Oil-collecting bees such as Rediviva neliana have long forelimbs which are used to mop up oil rewards from the twin spurs of the genus Diascia (Scrophulariaceae) and some orchids. When Steiner and Whitehead (1990) examined multiple populations of the bee and various Diascia species, they found a strong pattern of covariation between the average foreleg length of the bees and the spur length in Diascia populations.

Since then, even more spectacular examples of morphological covariation have been found in the tube and tongue lengths of long-tongued flies and the flowers that they visit (Anderson and Johnson 2008, 2009; Pauw et al. 2009). The tongues of these flies can be many times the length of their own bodies, and in the case of Moegistorynchus longirostris (Fig. 3) the tongues can reach a length exceeding 85 millimeters. In both of these systems, the tube and tongue lengths of interacting species show two- or three-fold variation across the landscape but were nevertheless closely correlated (Anderson and Johnson 2008, 2009; Pauw et al. 2009) (Figs. 4 and 5). These results have been interpreted as evidence to suggest that coevolution can generate geographic diversification in the morphology of interacting species pairs which may ultimately play an important role in the speciation process. Coevolution may also conceivably result in geographically divergent outcomes if abiotic factors, such as climate, determine how far the coevolutionary process is able to proceed.

The three pollination systems mentioned above were good candidate systems to study coevolution because the plants in all three species were dependent on a single pollinator species in each population, and the pollinators were all heavily dependent on these abundant plants as a source of food. Thus it can be imagined that the process of reciprocal selection operates. Although geographic covariation is consistent with the model of how tube-tongue length coevolution proceeds, demonstrating geographic covariation alone does not demonstrate that coevolution has occurred. This is because many other processes can also give rise to the geographic covariation of traits. If environmental factors have exactly the same effects on tube length and tongue length morphology, or even on other correlated body or floral traits, then tubes and tongues could correlate with each other without any reciprocal adaptation being involved in the process. Environmental variables and potentially correlated morphological traits (also see Steiner and Whitehead 1990, 1991) 
Fig. 4 Geographical variation in trait values for $Z$. microsiphon and $P$. ganglbaueri.

Redrawn from Anderson and Johnson (2008)

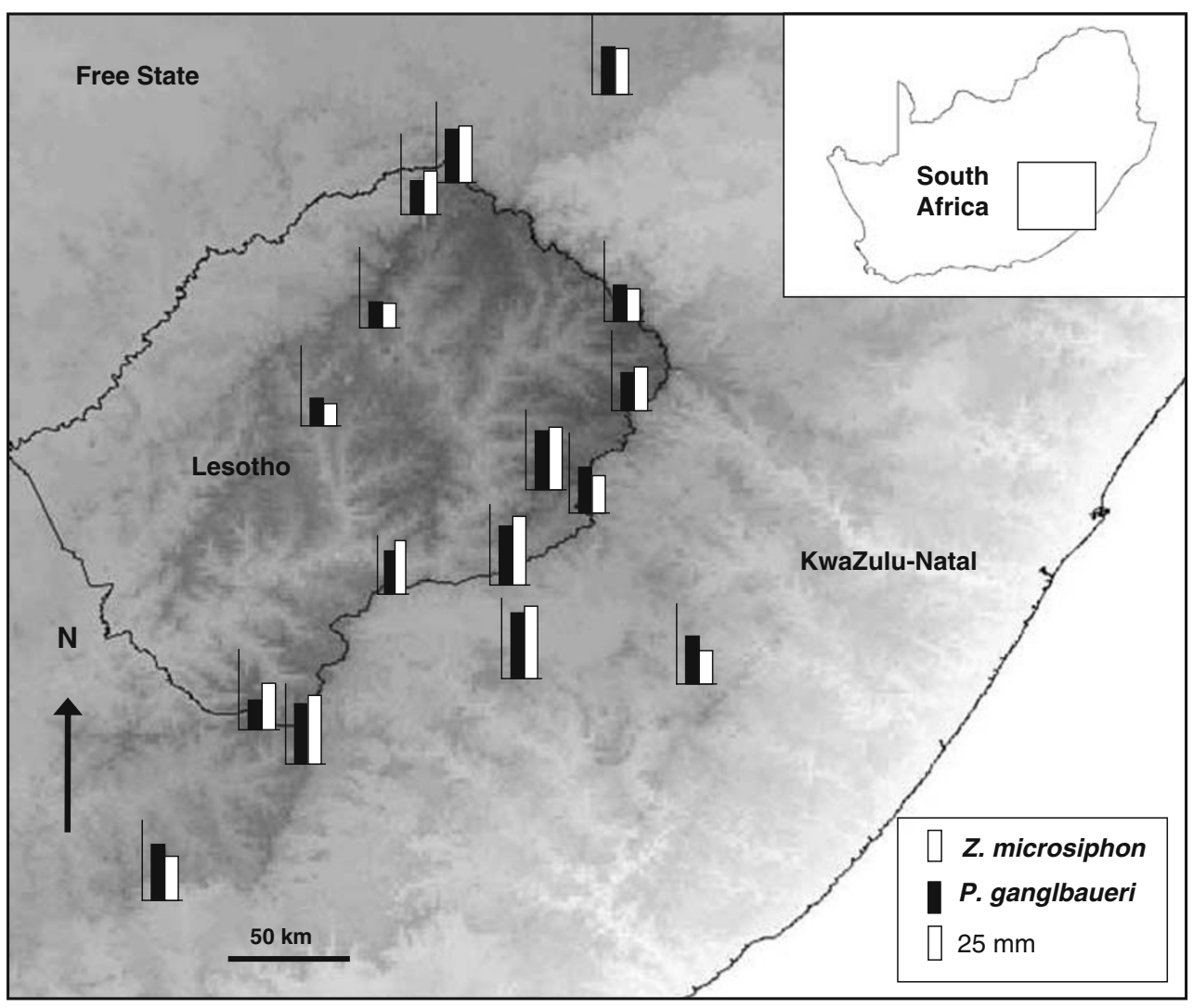

were incorporated into the models used to explain the geographic variation in the tongue lengths of the longtongued fly Prosoeca ganglbaueri and its host plant Zaluzianskya microsiphon (Anderson and Johnson 2008). Despite the inclusion of these additional variables, tube length was best explained by the tongue lengths of the insect pollinators and vice versa, which supports the coevolution hypothesis. Furthermore, in one of these systems, the hypothesis of local co-adaptation was supported by reciprocal translocation experiments in which short-tubed plants translocated to sites with longer-tongued flies performed poorly relative to local forms with long tubes (Anderson and Johnson 2008, 2009).

Patterns of geographic trait covariation can also arise if one species adapts to another but not vice versa (i.e., unilateral evolution instead of coevolution). Perhaps the best documented case is the guild of long-proboscid flypollinated plants studied by Anderson et al. (2005) and Anderson and Johnson (2009). Anderson et al. (2005) demonstrated that the long-tongued fly $P$. ganglbaueri was the main pollinator of $Z$. microsiphon as well as the orchid Disa nivea. One difference between these two plants is that Z. microsiphon offers nectar rewards to its pollinators, but D. nivea offers no rewards. In a case of floral Batesian mimicry, $D$. nivea superficially resembles the rewarding plant Z. microsiphon and in so doing deceives pollinators into visiting it through mistaken identity. As a result, fly pollinators gain no benefit in matching the tube lengths of these rewardless orchids, but the orchid spurs nevertheless match the tongues of the flies as this maximizes the efficiency of pollen transfer (Fig. 5). Thus, although the orchids are not directly involved in a coevolutionary race with the flies, coevolution still affects them indirectly because they have to keep pace with the coevolutionary

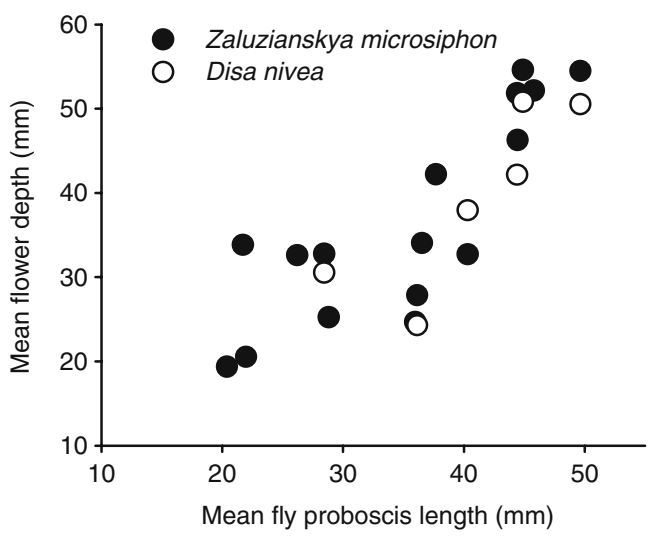

Fig. 5 Covariation in the length of the proboscis of the nemestrinid fly $P$. ganglbaueri and two plant species that it pollinates, Z. microsiphon, the main nectar source for the flies, and $D$. nivea, a nonrewarding orchid which tracks the evolution of the fly proboscis length. Values represent means for various populations in the Drakensberg Mountains of South Africa (see Fig. 3). Redrawn from Anderson and Johnson (2008, 2009) 
race between the flies and other rewarding plants, leading to identical patterns of geographic trait matching (Fig. 5).

Rewardless plants may not be the only plants tracking the evolutionary races of others. Entire guilds of less common plants may track coevolutionary races instead of driving them because they are too rare to exert much selective pressure on the pollinators. Anderson and Johnson (2009) and Pauw et al. (2009) found local convergence of floral morphology among unrelated plant species in the same community. Character traits such as tube length were more similar among different species in the same communities than they were between different populations of the same species. The important message from this is that trait evolution in coevolving species can have implications for other guild members that either track the evolution of these traits or become incorporated into these guilds. One of us recently argued that these pollination guilds can be interpreted as evolving niches which drive diversification (Johnson 2010).

\section{Macroevolution}

The idea that coevolution between angiosperms and insects led to diversification of both groups has long been popular. It was first proposed by the nineteenth century French paleontologist Gaston de Saporta who argued that "insects and plants have therefore been simultaneously cause and effect through their connection with each other" (cited in Friedman 2009). De Saporta's hypothesis was enthusiastically endorsed by Darwin in letters that he wrote to de Saporta and Hooker towards the end of his life (Friedman 2009).

Studies suggest that plant diversification has indeed been stimulated by interactions with animal pollinators (Dodd et al. 1999). The radiation of angiosperms does not appear to have accelerated the origins of higher taxa of flower-feeding insects (Labandeira and Sepkoski 1993), but it would be hard not to accept that the species-level diversification of some insects groups such as bees was stimulated by the expanding availability of angiosperm floral niches, as shown in the elegant studies of oil-bees by Steiner and Whitehead (1990, 1991).

Studies which have traced the evolution of floral traits using phylogenies of particular plant groups suggest that shifts between different pollinators, rather than coevolution with them, has been the main driver of diversification. In Aquilegia, the direction of floral spur length evolution has been from short to long and was associated with shifts from bee to hummingbird to hawkmoth pollination through time (Whittall and Hodges 2007). Furthermore, the divergence has been very recent, suggesting that Aquilegia species adapted to pollinators with preexisting trait values.

Both the coevolution and pollinator shift models are often misunderstood to imply that selection will always occur in the direction of more extreme traits, but reversals are a well-known aspect of floral macroevolution (Stebbins 1970). Evolutionary transitions from long to shorter floral tubes are evident in many plant groups, including Angraecum and its allies where it is associated with shifts from hawkmoth to bird pollination (Micheneau et al. 2008, 2009). This macroevolutionary pattern is supported by microevolutionary evidence that selection can favor shorter flowers tubes when the current pollinators have short tongues (Bloch and Erhardt 2008)

\section{Conclusions}

Studies carried out over the past two decades have confirmed both Darwin's mechanism for pollinatormediated selection on tube length in flowers and the concept of a geographic mosaic of coevolution between pollinators and plants with food-rewarding flowers. These studies, alongside others dealing with brood-site pollination mutualisms (Pellmyr et al. 1996; Weiblen 2002) and antagonistic (interactions in which one partner is harmed) seed-predation systems (Toju and Sota 2006), confirm that coevolution can be an important driver of phenotypic divergence among populations of strongly interacting species.

Coevolution (two-sided evolution) and pollinator shifts (one-sided evolution) have been viewed as alternative explanations for the evolution of floral traits (Wasserthal 1997; Nilsson 1998; Whittall and Hodges 2007). However, traits of species that show strong reciprocal interactions over long periods of time may be shaped largely by coevolution, while evolution is probably largely one-sided in the case of nonrewarding guild members or rewarding species that are either naturally rare or which have made recent shifts into established guilds (Johnson and Steiner 1997; Anderson and Johnson 2009; Pauw et al. 2009). Thus it seems that coevolution can operate alongside other onesided evolutionary processes to shape the traits of interacting species.

\section{References}

Alexandersson R, Johnson SD. Pollinator mediated selection on flowertube length in a hawkmoth-pollinated Gladiolus (Iridaceae). Proc R Soc B. 2002;269:631-6.

Anderson B, Johnson SD. The geographical mosaic of coevolution in a plant-pollinator mutualism. Evolution. 2008;62:220-5.

Anderson B, Johnson SD. Geographical covariation and local convergence of flower depth in a guild of fly-pollinated plants. New Phytol. 2009;182:533-40.

Anderson B, Johnson SD, Carbutt C. Exploitation of a specialized mutualism by a deceptive orchid. Am J Bot. 2005;92:1342-9.

Bloch D, Erhardt A. Selection toward shorter flowers by butterflies whose probosces are shorter than floral tubes. Ecology. 2008;89:2453-60. 
Darwin C. On the origin of species by means of natural selection or the preservation of favoured races in the struggle for life. London: John Murray; 1859.

Darwin CR. On the various contrivances by which British and foreign orchids are fertilized by insects, facsimile edn. London: John Murray; 1862.

Darwin C (1867) Letter 5648-Darwin, C. R. to Wallace, A. R., 12-13 Oct. http://www.darwinproject.ac.uk/entry-5648. Accessed 4 Jan 2010.

Dodd ME, Silvertown J, Chase MW. Phylogenetic analysis of trait evolution and species diversity variation among angiosperm families. Evolution. 1999;53:732-44.

Ehrlich PR, Raven PH. Butterflies and plants: a study in coevolution. Evolution. 1964;18:586-608.

Friedman WE. The meaning of Darwin's "abominable mystery". Am J Bot. 2009;96:5-21.

Gomez JM, Perfectti F, Bosch J, Camacho JPM. A geographic selection mosaic in a generalized plant-pollinator-herbivore system. Ecol Monogr. 2009;79:245-63.

Grant V, Grant KA. Flower pollination in the Phlox family. New York: Columbia University Press; 1965.

Johnson SD. Pollinator-driven speciation in plants. In: Harder LD, Barrett SCH, editors. The ecology and evolution of flowers. Oxford: Oxford University Press; 2006. p. 295-310.

Johnson SD. The pollination niche and its role in the diversification and maintenance of the southern African flora. Phil Trans R Soc B. 2010;365:499-516.

Johnson SD, Steiner KE. Long-tongued fly pollination and evolution of floral spur length in the Disa draconis complex (Orchidaceae). Evolution. 1997;51:45-53.

Labandeira CC, Sepkoski JJ. Insect diversity in the fossil record. Science. 1993;261:310-5.

Martins DJ, Johnson SD. Hawkmoth pollination of aerangoid orchids in kenya, with special reference to nectar sugar concentration gradients in the floral spurs. Am J Bot. 2007;94:650-9.

Micheneau C, Carlsward BS, Fay MF, Bytebier B, Pailler T, Chase MW. Phylogenetics and biogeography of Mascarene angraecoid orchids (Vandeae, Orchidaceae). Mol Phylogenet Evol. 2008;46:908-22.

Micheneau C, Johnson SD, Fay MF. Orchid pollination: From Darwin to the present day. Bot J Linn Soc. 2009;161:1-19.

Muchhala N, Thomson JD. Going to great lengths: selection for long corolla tubes in an extremely specialized bat-flower mutualism. Proc R Soc B-Biol Sci. 2009;276:2147-52.

Müller H. Proboscis capable of sucking the nectar of Angraecum sesquipedale. Nature. 1873;8:223.
Nilsson LA. The evolution of flowers with deep corolla tubes. Nature. 1988:334:147-9.

Nilsson LA. Deep flowers for long tongues. Trends Ecol Evol. 1998;13:259-60.

Nilsson LA, Jonsson L, Rason L, Randrianjohany E. Monophily and pollination in Anaraocum arachnites Schlrt. (Orchidaceae) in a guild of long-tongued hawk-moths (Sphingidae) in Madagascar. Biol J Linn Soc. 1985;26:1-19.

Pauw A, Stofberg J, Waterman RJ. Flies and flowers in Darwin's race. Evolution. 2009;63:268-79.

Pellmyr O, Thompson JN, Brown JM, Harrison RG. Evolution of pollination and mutualism in the yucca moth lineage. Am Nat. 1996;148:827-47.

Sakai S. A review of brood-site pollination mutualism: plants providing breeding sites for their pollinators. J Plant Res. 2002;115:161-8.

Schemske DW. Limits to specialization and coevolution in plantanimal mutualisms. In: Nitecki MH, editor. Coevolution. Chicago: University of Chicago Press; 1983. p. 67-109.

Stebbins GL. Adaptive radiation of reproductive characteristics in angiosperms. I. Pollination mechanisms. Annu Rev Ecol Syst. 1970;1:307-26.

Steiner KE, Whitehead VB. Pollinator adaptation to oil-secreting flowers - Redivivia and Diascia. Evolution. 1990;44:1701-7.

Steiner KE, Whitehead VB. Oil flowers and oil bees: further evidence for pollinator adaptation. Evolution. 1991;45:1493-501.

Thompson JN. The coevolutionary process. Chicago: Chicago University Press; 1994.

Thompson JN. The geographic mosaic of coevolution. Chicago: University of Chicago Press; 2005.

Thompson JN, Cunningham BM. Geographic structure and dynamics of coevolutionary selection. Nature. 2002;417:735-8.

Toju H, Sota T. Imbalance of predator and prey armament: Geographic clines in phenotypic interface and natural selection. Am Nat. 2006;167:105-17.

Vazquez DP, Aizen MA. Asymmetric specialization: A pervasive feature of plant-pollinator interactions. Ecology. 2004;85:1251-7.

Wallace AR. Creation by law. Q J Sci. 1867;4:470-88.

Wasserthal LT. The pollinators of the Malagasy star orchids Angraecum sesquipedale, A. sororium and A. compactum and the evolution of extremely long spurs by pollinator shift. Botanica Acta. 1997;110:343-59.

Weiblen GD. How to be a fig wasp. Annu Rev Entomol. 2002;47:299-330.

Whittall JB, Hodges SA. Pollinator shifts drive increasingly long nectar spurs in columbine flowers. Nature. 2007;447:706-U712. 